\title{
COMPOSIÇÃO DA CARTEIRA DE CRÉDITO DAS AGÊNCIAS ESTADUAIS DE FOMENTO: MUDANÇAS DO PERFIL DOS TOMADORES DE CRÉDITO (2012 | 2018)
}

FALCHETTI, Yan Watanabe ${ }^{1}$ GOMES, Erasmo José ${ }^{2}$

Recebido em: 2020.03 .20

Aprovado em: 2020.10 .20

ISSUE DOI: $10.3738 / 1982.2278 .3763$

RESUMO: O presente estudo teve como objetivo identificar a composição da carteira de crédito das agências estaduais de fomento ao desenvolvimento e sua caracterização nos anos de 2012 e 2018 A questão central a ser analisada é o perfil dos tomadores de crédito para o desenvolvimento regional por meio do financiamento das agências estaduais de desenvolvimento e sua modificação entre os anos analisados.

Palavras-Chave: Desenvolvimento. Agências de Fomento. Carteira de crédito.

\section{COMPOSITION OF THE CREDIT PORTFOLIO OF STATE DEVELOPMENT AGENCIES: CHANGE IN THE BORROWERS PROFILE'S (2012 | 2018)}

SUMMARY: The purpose of this study was to identify the composition of the credit portfolio of state development agencies and its characterization in the years 2012 and 2018 . The central issue to be analyzed is the profile of borrowers for regional development through the financing of state development agencies and their modification between the years analyzed.

Keywords: Development. Development Agencies. Credit portfolio.

\section{INTRODUÇÃO}

As agências de fomento surgiram no Brasil a partir do processo de reestruturação do segmento bancário nacional, no âmbito do Programa de Incentivo à Redução da Presença do Setor Público na Atividade Financeira (PROES), instituído por meio da Medida Provisória (MP) $\mathrm{n}^{\mathrm{o}}$ 1.514, de 07 de agosto de 1996, suas reedições e sucedâneas sendo, a última, a MP 2.192, editada em 24 de agosto de 2001. O PROES previa que as instituições financeiras sob o controle dos estados seriam extintas, privatizadas ou transformadas em instituições financeiras dedicadas ao financiamento de capital fixo e de giro associado a projetos no País, denominadas agências de fomento (BANCO CENTRAL DO BRASIL, 2019).

No ano de 2001 foi disciplinado, por meio da Resolução 2.828 do Banco Central do Brasil, o funcionamento das agências de fomento. Estas instituições não bancárias atuam com taxas de juros mais baixas, facilitando o crédito para programas de desenvolvimento e

\footnotetext{
${ }^{1}$ Graduando em Administração na Faculdade de Economia, Administração e Contabilidade de Ribeirão Preto da Universidade de São Paulo | FEA-RP/USP

${ }^{2}$ Professor da Faculdade de Economia, Administração e Contabilidade de Ribeirão Preto da Universidade de São Paulo $\mid$ FEA-RP/USP.
} 
financiamento para capital fixo e de giro de profissionais liberais e micro e pequenas empresas nos mais variados setores da economia que enfrentam restrições internas de financiamento de longo prazo.

Atualmente, o Brasil possui 16 agências de desenvolvimento, distribuídas por regiões do país e estados subnacionais, como segue: Nordeste (Alagoas, Bahia, Pernambuco, Piauí e Rio Grande do Norte), Norte (Amapá, Amazonas, Roraima e Tocantins), Sudeste (São Paulo e Rio de Janeiro), Sul (Paraná, Santa Catarina e Rio Grande do Sul) e Centro-Oeste (Goiás e Mato Grosso), conforme dados do Banco Central do Brasil.

Diante da importância dessas instituições para o desenvolvimento regional, entende-se necessária a análise da composição da carteira de crédito das agências estaduais de fomento e o perfil dos tomadores de crédito responsáveis pelo desenvolvimento regional, analisando sua mudança nos anos de 2012 e 2018.

\section{REVISÃO DE LITERATURA}

A criação do Banco Nacional de Desenvolvimento Econômico (BNDE), no ano de 1952, iniciou um processo de desenvolvimentismo para a economia brasileira, uma vez que as empresas privadas não eram adequadas para suprir recursos de investimento e conceder financiamento.

Nas décadas de 1950 e 1960, surgiu um sistema nomeado por Cavalcante (2007) de "sistema nacional de bancos de desenvolvimento" no qual estavam inseridos: bancos federais de abrangência nacional, um banco interestadual de desenvolvimento e bancos estaduais de desenvolvimento. Estas instituições atuavam como importantes articuladores responsáveis por executar uma política de crédito do setor privado.

A Reforma Bancária de 1964-1965, tinha como objetivo criar um sistema financeiro privado capaz de financiar o desenvolvimento econômico. Por sua vez, o BNDE após as reformas voltou seu olhar para o financiamento ao setor privado e buscou aumentar sua capilaridade regional, tanto através da disseminação de operações de repasse, quanto por meio de sua atuação conjunta com instituições financeiras regionais. (CAVALCANTE, 2007).

Embora o objetivo inicial do BNDE fosse financiar investimentos do setor público, o setor privado absorveu, ao final da década de 1970, mais de $80 \%$ dos financiamentos concedidos pela instituição. (NAJBERG, 2002).

De acordo com Ferreira (2017), no ano de 1982, a crise de insolvência iniciada no México se espalhou rapidamente por diversos países latinos americanos, incluindo o Brasil. Como reflexo, a visão neoliberal do papel do Estado começa a ganhar espaço, tendo como resultado 
reformas liberalizantes. Com isto, desenhou-se um movimento de estímulos à redução da presença do setor público estadual na atividade bancária, em que bancos estaduais seriam privatizados, extintos ou transformados em agências de fomento (RIBEIRO, 2002).

As agências de fomento surgiram no Brasil a partir do processo de reestruturação do segmento bancário nacional, no âmbito do Programa de Incentivo à Redução da Presença do Setor Público na Atividade Financeira.

Em 2001, o assunto foi disciplinado pela Resolução 2.828, de 30 de março de 2001 (BCB, 2001), que prevê o estabelecimento e operação de agências de financiamento. Essas instituições não bancárias operam com taxas de juros mais baixas, facilitando o crédito para programas de desenvolvimento e financiamento de capital fixo e capital de giro para profissionais e micro e pequenas empresas em vários setores da economia que enfrentam restrições de financiamento interno de longo prazo.

De acordo com a esta Resolução, as agências de fomento devem ser constituídas sob a forma de sociedade anônima de capital fechado e ter seu funcionamento subordinado às regras do Banco Central do Brasil.

Entre potenciais beneficiários de financiamentos concedidos pelas agências de fomento estão projetos de infraestrutura, profissionais liberais, micro e pequenas empresas, nos segmentos da indústria, comércio, agronegócio, turismo e informática. A agência de fomento pode, inclusive, abrir linhas de crédito para os municípios do Estado em que estiver sediada para financiar projetos de interesse da população. Em caráter excepcional, quando o empreendimento visar benefícios de interesse comum, as agências de fomento podem prestar assistência a programas e projetos desenvolvidos em estado limítrofe à sua área de atuação.

São atividades permitidas às agências de fomento (BCB, 2001):

- Financiamento para o desenvolvimento de empreendimentos de natureza profissional, comercial ou industrial, de pequeno porte, inclusive a pessoas físicas;

- Financiamento de capitais fixo e de giro associados a projetos;

- Operações de crédito rural;

- Cessão de créditos;

- Prestação de garantias em operações compatíveis com o objeto social;

- Prestação de serviços de consultoria e de agente financeiro;

- Prestação de serviços de administrador de fundos de desenvolvimento;

- Operações específicas de câmbio;

- Aplicação de disponibilidades de caixa em títulos públicos federais, ou em cotas de fundos de investimento cujas carteiras estejam representadas exclusivamente por títulos públicos federais, desde que assim conste nos regulamentos dos fundos; 
- Aquisição de créditos oriundos de operações compatíveis com o objeto social;

- Participação societária em sociedades empresárias não integrantes do sistema financeiro;

- Swap para proteção de posições próprias;

- Operações de arrendamento mercantil;

- Integralização de cotas de fundos que tenham participação da união:

- Aplicação em operações de micro finanças (DIM).

No tocante às suas obrigações, as agências de fomento, além de recursos próprios, em operações passivas, só podem empregar recursos provenientes de fundos e programas oficiais, dos orçamentos federal, estaduais e municipais, de organismos e instituições financeiras nacionais e internacionais de desenvolvimento. É vedada a captação de recursos junto ao público. Adicionalmente, essas instituições devem constituir e manter, permanentemente, fundo de liquidez equivalente, no mínimo, a 10\% do valor de suas obrigações, a ser integralmente aplicado em títulos públicos federais (BCB, 2019). Atualmente, o Brasil conta com 16 agências de fomento, conforme apresentado na Tabela 1.

Tabela 1: Agências de fomento, por ano de criação.

\begin{tabular}{clc}
\hline $\begin{array}{c}\text { Ano de } \\
\text { Criação }\end{array}$ & \multicolumn{1}{c}{ Denominação } & Sigla \\
\hline 1973 & Agência de Fomento do Estado de Santa Catarina S.A. & BADESC \\
1997 & Agência de Fomento do Estado de Roraima S.A. & DESENVOLVE RR \\
1997 & Agência de Fomento do Paraná S.A. & FOMENTO PARANÁ \\
1997 & Badesul Desenvolvimento S.A - Agência de Fomento/RS & BADESUL \\
1998 & Agência de Fomento do Amapá S.A. & AFAP \\
1998 & Agência de Fomento do Estado do Amazonas S.A. & AFEAM \\
1999 & Agência de Fomento de Goiás S/A & GOIÁS FOMENTO \\
1999 & Agência de Fomento do Rio Grande do Norte S.A. & AGN \\
2001 & Agência de Fomento do Estado de São Paulo S.A & DESENVOLVE SP \\
2001 & Agência de Fomento do Estado da Bahia S.A. & DESENBAHIA \\
2002 & Agência de Fomento do Estado do Rio de Janeiro S.A. & AGERIO \\
2003 & Agência de Fomento do Estado de Mato Grosso S/A & DESENVOLVE MT \\
2005 & Agência de Fomento do Estado do Tocantins S.A. & FOMENTO \\
2009 & Agência de Fomento de Alagoas S.A. & DESENVOLVE \\
2010 & Agência de Fomento e Desenvolvimento do Piauí S.A. & PIAUÍ FOMENTO \\
2011 & Agência de Fomento do Estado de Pernambuco S.A. & AGEFEPE \\
\hline
\end{tabular}

Fonte: Banco Central do Brasil (2019)

Cabe observar que algumas das instituições foram cridas originalmente como bancos de desenvolvimento para, anos mais tarde, assumirem a atual configuração de agências de fomento. São os casos, por exemplo, da Agência de Fomento do Estado de Santa Catarina S.A, criada em Nucleus, v.17, n.2, out.2020 
1973 como Banco de Desenvolvimento do Estado de Santa Catarina S.A. (BADESC) e a Agência de Fomento/RS, originalmente instituída, no ano de 1973, como Banco de Desenvolvimento do Estado do Rio Grande do Sul S.A. (BADESUL). Com relação à distribuição regional das agências de fomento, tem-se a situação apresentada no Quadro 2.

Tabela 2: Distribuição regional das agências de fomento

\begin{tabular}{|c|c|c|c|c|}
\hline Região & Estados & $\begin{array}{l}\text { Agências } \\
\text { de } \\
\text { Fomento }\end{array}$ & $\begin{array}{c}\text { Part. } \\
\text { Relativa } \\
(\%)\end{array}$ & $\begin{array}{c}\text { Estados da } \\
\text { Região com } \\
\text { Agências de } \\
\text { Fomento }(\%)\end{array}$ \\
\hline Nordeste & $\begin{array}{l}\text { PE, PI, BA, } \\
\text { AL, RN }\end{array}$ & 5 & 31,3 & (5/9) 55,6 \\
\hline Norte & $\begin{array}{c}\mathrm{AP}, \mathrm{AM}, \mathrm{RR}, \\
\mathrm{TO}\end{array}$ & 4 & 25,0 & (4/7) 57,1 \\
\hline Sul & PR, RS, SC & 3 & 18,8 & $(3 / 3) 100$ \\
\hline Centro-Oeste & $\mathrm{GO}, \mathrm{MT}$ & 2 & 12,5 & $(2 / 4) 50$ \\
\hline Sudeste & RJ, SP & 2 & 12,5 & (2/4) 50 \\
\hline Total & - & 16 & 100 & - \\
\hline
\end{tabular}

Fonte: Elaborado pelo Autor

Verifica-se que os estados das regiões Norte e Nordeste do país contam com o maior número absoluto de agências de fomento. Juntas, essas duas regiões contam nove instituições, ou $56,3 \%$ do total de instituições dessa natureza, sendo cinco (ou 31,3\%) no Nordeste e quatro ou (25\%), na Região Norte. As regiões Sul e Sudeste contam com cinco instituições, ou 31,3\% do total, sendo três, ou $18,8 \%$ do total, na região Sul e duas ou $12,5 \%$, na região Sudeste. A região Centro-Oeste, conta duas instituições, ou $12,5 \%$ do total.

Já, com relação ao número de agências de fomento, segundo o número de estados que compõe cada região, a região Sul apresenta a maior proporção, com 100\% dos Estados tendo uma agência de fomento (Rio Grande do Sul, Santa Catarina e Paraná), seguido pela região Norte, com $57,1 \%$ (ou cinco estados de um total de sete), Nordeste, com 55,6\% (ou cinco estados de um total de nove), Centro-Oeste e Sudeste com 50\% cada (ou dois estados de um total de quatro).

Não menos importante, cabe observar que as agências de fomento integram o chamado Sistema Nacional de Fomento (SNF), composto por bancos públicos federais, bancos de desenvolvimento controlados por estados da federação, bancos cooperativos, bancos públicos comerciais estaduais com carteira de desenvolvimento e agências de fomento, além da Financiadora de Estudos e Projetos (Finep) e do Sebrae (ABDE, 2019). Assim, na categoria "bancos de desenvolvimento controlados por estados da federação", tem-se as seguintes instituições: Banco de Desenvolvimento de Minas Gerais S.A. (BDMG), Banco de Desenvolvimento do Espirito Santo S.A. (BANDES) e Banco Regional de Desenvolvimento do Extremo Sul (BDRE). Já, na categoria "bancos públicos federais", tem-se as seguintes 
instituições: Banco do Nordeste do Brasil (BNB), Banco da Amazônia (BASA), Banco do Brasil (BB), Banco Nacional de Desenvolvimento Econômico e Social (BNDES) e Caixa Econômica Federal (CAIXA).

As Agências de Fomento são classificadas atualmente pelo Banco Central do Brasil com base na Resolução $n^{0}$ 4.553, de 30 de janeiro de 2017 (BCB, 2017), que "Estabelece a segmentação do conjunto das instituições financeiras e demais instituições autorizadas a funcionar pelo Banco Central do Brasil para fins de aplicação proporcional da regulação prudencial”. A referida Resolução prevê cinco segmentos de porte, de S1 a S5, expressos pela razão entre o valor da Exposição Total (ou o valor do Ativo Total, a depender do caso) e o valor do PIB do Brasil a preços de mercado e valores correntes divulgado pelo Instituto Brasileiro de Geografia e Estatística (IBGE). Adotando tais critérios, todas as 16 Agências de Fomento brasileiras estão classificadas no segmento S4, o qual é composto pelas instituições de porte inferior a $0,1 \%$ (um décimo por cento) do PIB.

\section{METODOLOGIA}

Para alcançar os objetivos propostos, a pesquisa baseou-se em uma abordagem quantitativa, cujo procedimento de pesquisa adotado foi baseado na coleta e análise de dados de 16 agências estaduais de desenvolvimento, presentes em 16 estados da federação das cinco regiões do país, em 2012 e 2018. A coleta de dados foi realizada por meio do acesso ao banco de dados fornecido pelo Banco Central do Brasil (IF.Data). Os arquivos com estes dados foram baixados e processados, selecionando as variáveis de perfil dos tomadores de crédito que atendem ao objetivo da pesquisa, como distribuição de carteira entre Pessoas Físicas e Jurídicas, número de clientes, porte das empresas e distribuição da carteira por setores econômicos.

Após o levantamento, os dados foram tabulados em ferramentas básicas de estatística descritiva, utilizando como suporte a planilha de dados MS Excel. Após esse processo, as variáveis da carteira de crédito foram identificadas nos dois anos analisados e, finalmente, foram gerados os gráficos e tabelas para facilitar a análise visual dos dados que ilustram o perfil dos mutuários e suas mudanças ao longo do tempo.

Dessa forma, foi possível observar a mudança no perfil dos tomadores de crédito entre os anos analisados 2012 e 2018. Esse período foi selecionado devido a disponibilidade de dados pelo Banco Central do Brasil, sendo o primeiro ano da compilação e divulgação destes dados iniciado no ano de 2012 e o último resumo anual apresentado é referente ao exercício de 2018. Embora a análise da trajetória completa, ano a ano, tenha dados mais abrangentes da séria 
história, não altera o fato de que a última posição consolidada apresenta a atual situação vigente das agências de fomento e as condições de crédito oferecidas com vistas a promover o desenvolvimento regional.

\section{RESULTADOS}

Para todas as agências estaduais de desenvolvimento analisadas, o número de clientes e as operações de crédito aumentaram 120\% e 64\%, respectivamente. Em 2012, as agências possuíam 27.494 clientes e realizou 42.819 operações de crédito. Já no ano de 2018, foram registrados 60.603 clientes no período e o número de operações para 70.275.

Gráfico 1- Número total de clientes e operações de crédito (2012 | 2018)

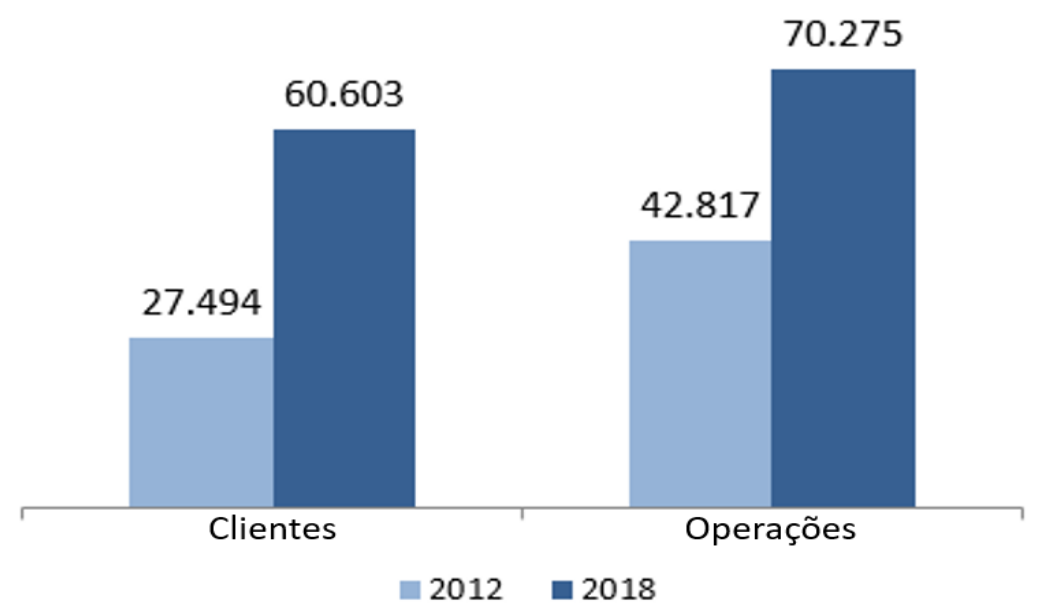

Fonte: Elaborado pelo Autor

No entanto, houve uma redução $(-6,6 \%)$ no total de crédito concedido por essas instituições. Com isto, é possível observar uma redução no oferecimento de crédito para seus tomadores e consequentemente uma pulverização deste crédito entre seus clientes.

Corroboram para a composição deste cenário a maior participação de Pessoa Física na concessão total de crédito, que cresceu moderadamente, passando de 15,4\% em 2012 para 17,8\% em 2018, uma vez que a participação de Pessoa Jurídica diminuiu - foi de 84,6\% em 2012 e passou para 82,2\% em 2018. Com isto, estas mudanças de perfil dos tomadores de créditos estimulou a elevação do risco do nível de operações de crédito.

Gráfico 2: Perfil da Carteira de Crédito - Tipo de Tomador (2012 | 2018) 


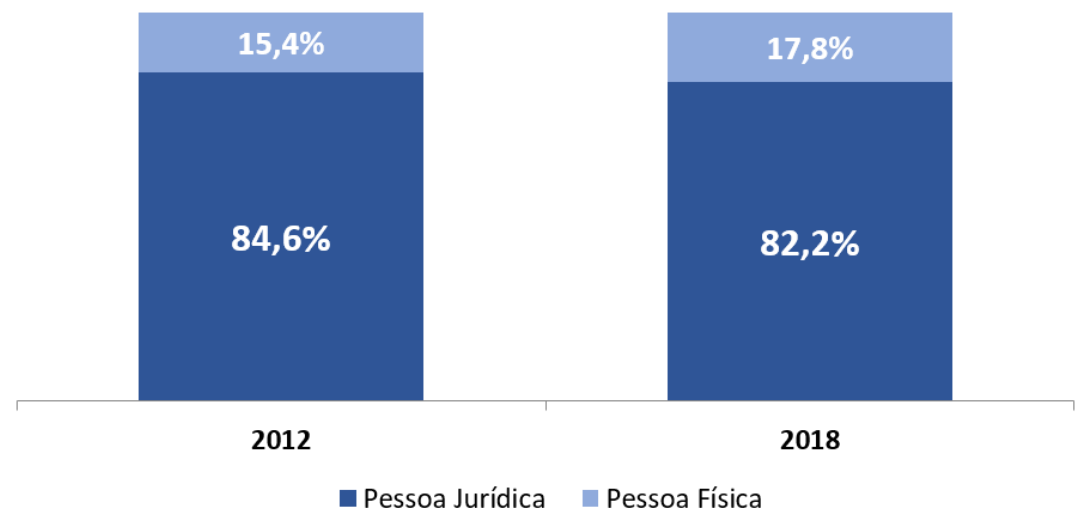

Fonte: Elaborado pelo Autor

Outro aspecto relevante é a classificação das operações de crédito estabelecida sob a Resolução n 2.682 de 21 de dezembro de 1999, publicada pelo Banco Central do Brasil, que leva em consideração os aspectos em relação ao devedor, seus garantidores e sua operação. As operações de crédito são classificadas em ordem crescente (AA, A, B, C, D, E, F, G, H), no qual considera-se a classificação nível H com o percentual de provisão de perdas em 100\% (BCB, 1999).

De fato, nota-se que entre os anos analisados, as operações de crédito classificadas como de menor nível de risco (AA) diminuíram 31\% (passando de 28,4\% em 2012 para 19,5\% em 2018), enquanto as de maior nível de risco $(\mathrm{H})$ tiveram um aumento expressivo de $234 \%$ (passando de 1,8\% em 2012 para 6,1\% em 2018) comparado em valores reais. Na Tabela 1 observa-se que a participação percentual nos anos de 2012 e 2018 teve significativa mudança, no qual a somatória de todas as agências de fomento passou a apresentar mais que $6 \%$ da sua carteira de crédito classificada como nível H de risco.

Tabela 3: Classificação de Risco 2012 | 2018: participação percentual sobre o total

\begin{tabular}{|c|c|c|c|c|c|c|c|c|c|c|}
\hline \multirow[b]{3}{*}{ UF | Ano } & \multicolumn{10}{|c|}{ Classificação de Risco (Continua) } \\
\hline & \multicolumn{2}{|c|}{$\mathbf{A A}$} & \multicolumn{2}{|c|}{$\mathbf{A}$} & \multicolumn{2}{|c|}{$\mathbf{B}$} & \multicolumn{2}{|c|}{ C } & \multicolumn{2}{|c|}{ D } \\
\hline & 2012 & 2018 & 2012 & 2018 & 2012 & 2018 & 2012 & 2018 & 2012 & 2018 \\
\hline $\mathbf{A L}$ & 0,0 & 0,0 & 73,7 & 51,8 & 2,3 & 14,7 & 2,7 & 9,0 & 4,4 & 2,7 \\
\hline AM & 0,0 & 0,0 & 3,7 & 14,7 & 30,6 & 21,3 & 34,9 & 23,6 & 20,6 & 1,7 \\
\hline $\mathbf{A P}$ & 0,0 & 0,0 & 71,9 & 70,9 & 7,2 & 3,9 & 3,8 & 6,5 & 3,4 & 1,9 \\
\hline BA & 33,7 & 26,0 & 17,1 & 20,0 & 33,0 & 27,5 & 6,9 & 17,8 & 0,9 & 1,8 \\
\hline GO & 0,0 & 0,0 & 10,9 & 12,3 & 75,9 & 74,9 & 4,4 & 3,8 & 1,8 & 2,9 \\
\hline MT & 0,0 & 0,0 & 31,4 & 32,8 & 35,8 & 38,4 & 15,6 & 9,8 & 4,1 & 4,3 \\
\hline $\mathbf{P E}$ & 0,0 & 0,0 & 3,1 & 23,5 & 16,9 & 58,2 & 74,6 & 9,1 & 0,0 & 0,7 \\
\hline PI & 0,0 & 0,0 & 87,8 & 45,1 & 4,4 & 17,5 & 3,7 & 5,7 & 1,4 & 9,2 \\
\hline PR & 10,6 & 14,1 & 76,4 & 63,1 & 12,3 & 13,0 & 0,3 & 5,9 & 0,1 & 1,1 \\
\hline
\end{tabular}




\begin{tabular}{ccccccccccc} 
RJ & 0,0 & 0,0 & 6,9 & 9,0 & 55,4 & 34,4 & 19,4 & 35,8 & 0,0 & 0,3 \\
RN & 0,0 & 0,0 & 56,2 & 70,9 & 9,3 & 4,9 & 1,9 & 5,2 & 1,9 & 1,9 \\
RR & NI & 0,0 & NI & 67,4 & NI & 3,5 & NI & 4,2 & NI & 9,0 \\
RS & 25,5 & 21,2 & 38,9 & 30,9 & 25,1 & 22,5 & 5,4 & 10,0 & 2,1 & 3,0 \\
SC & 46,4 & 30,6 & 32,6 & 33,4 & 6,7 & 24,1 & 3,7 & 3,9 & 1,3 & 0,6 \\
SP & 49,5 & 18,4 & 23,1 & 41,5 & 15,6 & 14,6 & 4,7 & 12,3 & 2,8 & 3,5 \\
TO & 0,0 & 0,0 & 41,8 & 14,8 & 28,2 & 36,2 & 8,0 & 32,5 & 5,8 & 5,4 \\
\hline Total & $\mathbf{2 8 , 4}$ & $\mathbf{1 9 , 5}$ & $\mathbf{3 8 , 2}$ & $\mathbf{3 7 , 0}$ & $\mathbf{2 1 , 3}$ & $\mathbf{2 1 , 3}$ & $\mathbf{5 , 3}$ & $\mathbf{1 0 , 5}$ & $\mathbf{2 , 1}$ & $\mathbf{2 , 3}$ \\
\hline
\end{tabular}

\begin{tabular}{|c|c|c|c|c|c|c|c|c|}
\hline \multicolumn{9}{|c|}{ Classificação de Risco (Conclusão) } \\
\hline \multirow[b]{2}{*}{ UF | Ano } & \multicolumn{2}{|c|}{$\mathbf{E}$} & \multicolumn{2}{|c|}{$\mathbf{F}$} & \multicolumn{2}{|c|}{$\mathbf{G}$} & \multicolumn{2}{|c|}{$\mathbf{H}$} \\
\hline & 2012 & 2018 & 2012 & 2018 & 2012 & 2018 & 2012 & 2018 \\
\hline $\mathbf{A L}$ & 4,2 & 5,0 & 2,2 & 12,6 & 3,9 & 0,4 & 6,8 & 3,9 \\
\hline $\mathbf{A M}$ & 1,9 & 1,7 & 3,9 & 0,0 & 0,1 & 0,4 & 4,4 & 36,5 \\
\hline $\mathbf{A P}$ & 2,4 & 1,8 & 1,2 & 1,6 & 1,1 & 3,4 & 9,1 & 10,1 \\
\hline BA & 1,0 & 1,3 & 1,0 & 0,2 & 0,1 & 0,1 & 6,5 & 5,3 \\
\hline GO & 0,5 & 3,1 & 1,2 & 1,1 & 0,3 & 0,5 & 5,0 & 1,3 \\
\hline MT & 1,0 & 5,1 & 0,7 & 1,3 & 1,2 & 0,3 & 10,3 & 8,1 \\
\hline PE & 5,3 & 2,6 & 0,0 & 0,9 & 0,0 & 1,9 & 0,0 & 1,1 \\
\hline PI & 0,0 & 4,6 & 0,4 & 2,6 & 0,5 & 2,9 & 1,9 & 12,4 \\
\hline PR & 0,1 & 0,6 & 0,0 & 0,3 & 0,0 & 0,2 & 0,1 & 1,6 \\
\hline RJ & 0,1 & 0,0 & 8,9 & 2,5 & 9,3 & 15,4 & 0,0 & 2,5 \\
\hline $\mathbf{R N}$ & 0,2 & 1,1 & 4,6 & 2,0 & 10,1 & 2,4 & 15,6 & 11,6 \\
\hline $\mathbf{R R}$ & NI & 2,8 & NI & 1,9 & NI & 1,5 & NI & 9,6 \\
\hline $\mathbf{R S}$ & 0,8 & 1,2 & 1,1 & 0,3 & 0,5 & 1,1 & 0,8 & 9,9 \\
\hline SC & 3,4 & 1,0 & 0,8 & 0,4 & 1,3 & 0,3 & 3,9 & 5,8 \\
\hline SP & 1,7 & 0,5 & 0,9 & 2,5 & 0,2 & 2,4 & 1,5 & 4,3 \\
\hline TO & 0,3 & 3,9 & 0,9 & 0,0 & 0,0 & 1,0 & 15,0 & 6,2 \\
\hline Total & 1,2 & 1,0 & 1,0 & 0,8 & 0,6 & 1,4 & 1,8 & 6,1 \\
\hline
\end{tabular}

Fonte: Elaborado pelo Autor

Após analisar o risco da carteira de crédito das agências de desenvolvimento, faz-se necessário compreender quais atividades estão sendo financiadas com estes recursos, promovendo o desenvolvimento regional. Pode-se observar na carteira de crédito de pessoas físicas, o destaque ao financiamento de atividades relacionadas aos setores rural e agroindustrial nos dois anos analisados.

Gráfico 3 - Carteira de Crédito Pessoa Física - Modalidade (2012 | 2018) 


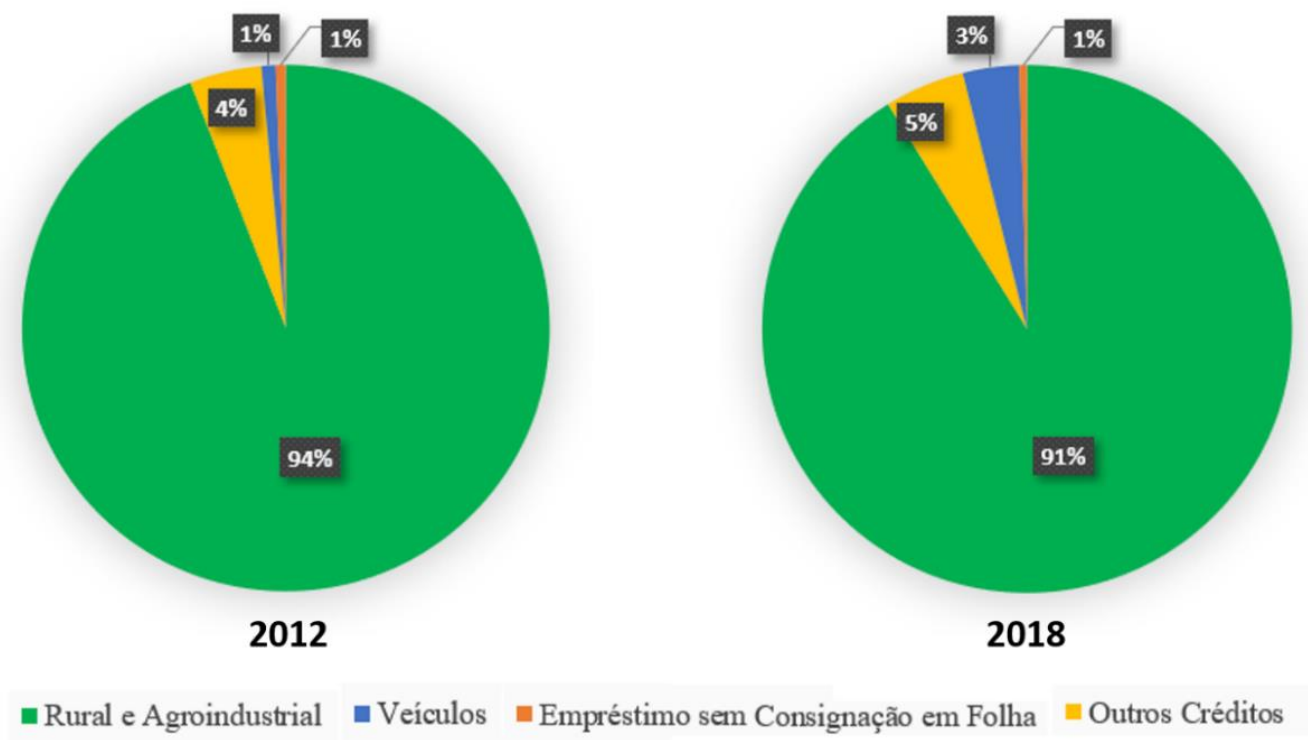

Fonte: Elaborado pelo Autor

Na carteira de crédito de Pessoa Jurídica, as principais atividades econômicas financiadas referem-se às Indústrias de Manufatura e Administração Pública, Defesa e Seguridade Social, que se destacam nos dois anos analisados. Com relação ao porte do negócio, há um crescimento significativo de tomadores de médio porte na carteira de crédito das agências estaduais de desenvolvimento no ano de 2018.

Gráfico 4- Carteira de Crédito Pessoa Física - Modalidade (2012 | 2018)

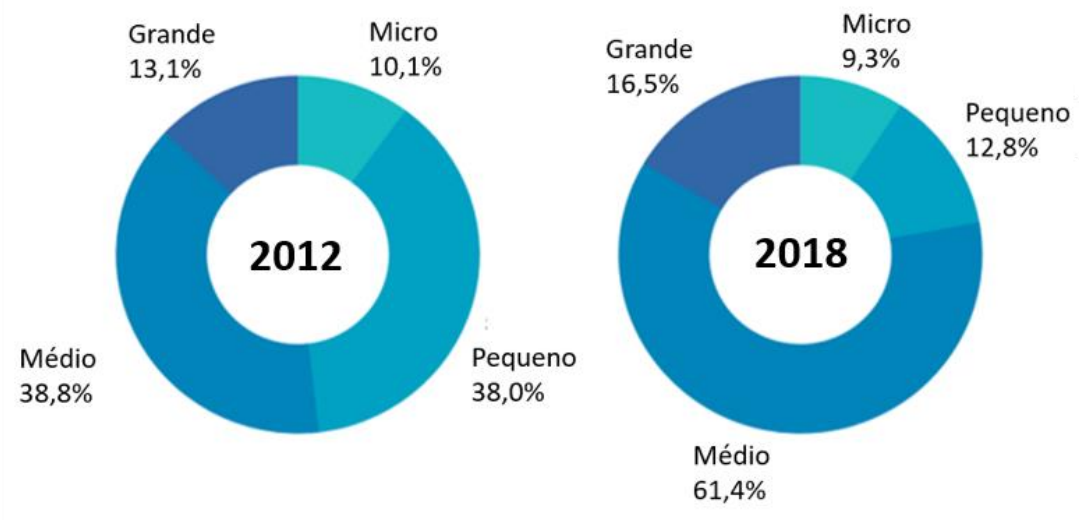

Fonte: Elaborado pelo Autor

\section{CONSIDERAÇÕES FINAIS}

Com base nos dados encontrados nesta pesquisa, foi possível concluir que os tomadores de crédito das agências estaduais de desenvolvimento mudaram de perfil entre os anos analisados, resultando em um maior nível de risco para as instituições e maior participação de Pessoa Física 
na captação de recursos para o desenvolvimento regional. Vale ressaltar a alta heterogeneidade operacional das agências estaduais de desenvolvimento, com seu amplo espectro de atividade e perfil de demanda de crédito.

Em um cenário de instabilidade política e econômica em meio a medidas de austeridade fiscal e baixo crescimento no PIB, com resultado de $1,1 \%$ no ano de 2019 , espera-se que este nível de risco continue em uma crescente devido a possibilidade de elevação da taxa de inadimplência, proporcionando análises mais criteriosas e classificações mais rigorosas.

Por outro lado, com o aquecimento da economia brasileira e elevação do PIB, as agências de fomento poderão expandir sua carteira de crédito, uma vez que os repasses tem a tendência de se elevarem juntamente com o crescimento econômico, reduzindo o risco da carteira e favorecendo o desenvolvimento regional.

\section{REFERÊNCIAS}

ALÉM, A. C. D.; MADEIRA, R. F. As instituições financeiras públicas de desenvolvimento e o financiamento de longo prazo. Revista do BNDES, Rio de Janeiro, n.43, p. 5-39, jun. 2015. Disponível em: <https://web.bndes.gov.br/bib/jspui/handle/1408/6244> . Acesso em: $20 \mathrm{fev}$. 2020.

ARAUJO, V. L. et al. O sistema brasileiro de instituições financeiras subnacionais para o desenvolvimento: um panorama. 2011. 40 f. Nova Economia, Belo Horizonte, 2013. BANCO CENTRAL DO BRASIL. Estatísticas sobre o Sistema Financeiro. IF Data: dados selecionados de instituições financeiras. Brasília, 2019. Disponível em:

<https://www3.bcb.gov.br/ifdata/>. Acesso em: 20 jan. 2020.

BANCO CENTRAL DO BRASIL. Resolução 2692, de 21 de dezembro de 1999. Dispõe sobre critérios de classificação das operações de crédito e regras para constituição de provisão para créditos de liquidação duvidosa. Disponível em:

<https://www.bcb.gov.br/pre/normativos/res/1999/pdf/res_2682_v2_L.pdf>. Acesso em: 10 mar. 2020.

BANCO CENTRAL DO BRASIL. Resolução 2828, de 30 de março de 2001. Dispõe sobre a constituição e o funcionamento de agências de fomento. Disponível em:

$\langle$ https://www.bcb.gov.br/pre/normativos/res/2001/pdf/res_2828_v4_L.pdf $>$. Acesso em: 20 jan. 2020.

CAVALCANTE, L. R. Seis personagens à procura de um autor: a inserção das agências de fomento e dos bancos estaduais de desenvolvimento no sistema financeiro no Brasil. Revista Desenbahia, Salvador, v. 4, n. 7, p. 7-33, 2007.

FERRAZ, J. C. et al. BNDES e o financiamento do desenvolvimento. Revista USP, São Paulo, n.93, p. 69-80, 2012.

FERREIRA, J. L. As elites no processo de desenvolvimento econômico regional: um estudo de caso na Agência de Fomento do Paraná. 2017. 
FREITAS, C. E. A experiência brasileira com instituições financeiras de desenvolvimento. Santiago de Chile: Comissão Econômica para a América Latina e o Caribe, 2005. Disponível em: <https://web.bndes.gov.br/bib/jspui/handle/1408/4682 >. Acesso em: 29 jan. 2020.

NAJBERG, S. Transformação do Sistema BNDES em financiador do setor privado nacional. In: BNDES. BNDES, um banco de idéias: 50 anos refletindo o Brasil. Rio de Janeiro: BNDES, 2002. p. 345-354.

TORRES FILHO, E. T.; COSTA, F. N. Financiamento de longo prazo no Brasil: um mercado em transformação. Rio de Janeiro: IPEA - Instituto de Pesquisa Econômica Aplicada, 2013. 54f. 